\title{
SOME IMPLICATIONS OF SELF-SELECTION FOR PREGNANCY
}

\author{
W. Z. BILLEWICZ
}

\section{MRC Reproduction and Growth Unit, Princess Mary Maternity Hospital, Great North Road, Newcastle NE2 3BD}

Though women have always been able to exercise some control over the risk of an unwanted pregnancy, the availability of effective and acceptable contraceptive methods and of abortion have made voluntary control of fertility by the individual simpler and more certain than ever.

The object of this paper is to examine the degree and features of self-selection for pregnancy in one community (Aberdeen) in the 'pre-pill' era and to assess the implications of an increase in fertility control for the interpretation of national and hospital statistics.

\section{MATERIALS}

The data consist of reproductive histories of 4,948 married women who had their first pregnancies in Aberdeen during the years 1949-54 and who were subsequently followed up until 1964 , i.e., for 10 to 15 years; details of this series were described by Billewicz and Thomson (1970). For present purposes, at most, four consecutive pregnancies per woman will be considered; only spontaneous abortions (later called miscarriages) are included. In order to avoid rejection of sequences including multiple pregnancies, such pregnancies were counted as one event and regarded as 'successful' if at least one infant survived the first week of life. To simplify calculations the perinatal mortality rate was defined as the number of stillbirths and deaths in the first week of life per 1,000 pregnancies which could have resulted in a viable infant and not per 1,000 live and stillbirths. Of the total of 12,071 pregnancies in this series, 925 resulted in miscarriages, 311 in perinatal deaths, and 10,835 in at least one infant who survived the first week.

The 'Pill' did not become generally available in Aberdeen until 1964, the last year covered by this study. Although other methods of contraception were previously available, they were not very effective (or not effectively used): Thompson and Illsley (1969) found that two-thirds of all pregnancies which occurred during the five years after a first birth in 1949 were 'unintended'. Though there was an unusually liberal policy towards abortion, pregnancies in married women were seldom terminated except in those already having four or more children and who also wanted sterilization.
The arguments which follow are not affected by the fact that, in common with all other series, the number of reported miscarriages is almost certainly too low. Data from the Registrar General for Scotland will be used when national statistics are considered.

\section{RESULTS}

Of the 4,948 first pregnancies, $100 \cdot 4$ per 1,000 were unsuccessful, i.e., ended in miscarriage or perinatal death. The perinatal mortality rate was 33.3 per 1,000 'viable' pregnancies and the miscarriage rate $69 \cdot 3$ per 1,000 total pregnancies.

The rates for higher pregnancy numbers, shown in Table I, must be presented in a slightly more complicated way, since previous pregnancies could end in various combinations of miscarriage, perinatal death or 'success'. The data show that increasing lack of success in previous pregnancies was accompanied by progressively greater lack of success (in terms of both unsuccessful pregnancies and perinatal deaths) in the current pregnancy. The two columns on the right-hand side of Table I show, in addition, that the chances of miscarriage in the current pregnancy increase with the number of miscarriages in previous pregnancies.

Table II (a) shows that the number of pregnancies a woman had within the follow-up period (10 to 15 years) depended to a considerable extent on how many of them were successful. Thus, for example, $58 \%$ of women with three successful pregnancies had no further recorded pregnancy after the third, whereas only $14 \%$ of those with three unsuccessful pregnancies 'gave up' at that point. That this pattern leads to selective disappearance of good reproducers is demonstrated in Table II (b): in each pregnancy number, women who went on to have another pregnancy had had lower rates of success than those who had no more recorded pregnancies. In other words, the higher the pregnancy number, the greater the proportion of women with poor reproductive histories.

If the periods of follow-up were not long enough to ensure that most women had almost completed their reproductive histories, the rate at which women appeared to 'retire' from childbearing might be seriously misleading. In this series, the behaviour 
TABLE I

PERINATAL MORTALITY, MISCARRIAGE, AND UNSUCCESSFUL PREGNANCY RATES ACCORDING TO PREVIOUS REPRODUCTIVE HISTORY

(All rates are for current pregnancies)

\begin{tabular}{|c|c|c|c|c|c|c|c|c|}
\hline \multirow{2}{*}{$\begin{array}{c}\begin{array}{c}\text { Current } \\
\text { Pregnancy }\end{array} \\
\text { Second } \quad \text {. }\end{array}$} & \multirow{2}{*}{$\begin{array}{c}\begin{array}{c}\text { Outcome of Previous } \\
\text { Pregnancies }\end{array} \\
\begin{array}{l}\text { Unsuccessful } \\
\text { Successful }\end{array}\end{array}$} & \multicolumn{2}{|c|}{$\begin{array}{c}\text { Unsuccessful } \\
\text { Pregnancy Rate }\end{array}$} & \multicolumn{2}{|c|}{$\begin{array}{l}\text { Perinatal } \\
\text { Mortality } \\
\text { Rate }\end{array}$} & \multirow{2}{*}{$\begin{array}{l}\begin{array}{c}\text { Previous } \\
\text { Miscarriages }\end{array} \\
\text { Miscarriage } \\
\text { None }\end{array}$} & \multicolumn{2}{|c|}{$\begin{array}{c}\text { Miscarriage } \\
\text { Rate }^{*}\end{array}$} \\
\hline & & $\begin{array}{r}157 \cdot 6 \\
91 \cdot 0\end{array}$ & $\begin{array}{r}(476) \\
(3,383)\end{array}$ & $\begin{array}{l}26 \cdot 7 \\
18 \cdot 8\end{array}$ & $\begin{array}{r}(412) \\
(3,134)\end{array}$ & & $\begin{array}{r}147 \cdot 9 \\
74 \cdot 7\end{array}$ & $\begin{array}{r}(338) \\
(3,521)\end{array}$ \\
\hline Third & $\begin{array}{l}2 \text { Unsuccessful } \\
1 \text { Unsuccessful } \\
2 \text { Successful }\end{array}$ & $\begin{array}{r}305 \cdot 6 \\
139 \cdot 1 \\
81 \cdot 9\end{array}$ & $\begin{array}{r}(72) \\
(575) \\
(1,563)\end{array}$ & $\begin{array}{l}74 \cdot 1 \\
25 \cdot 6 \\
19 \cdot 8\end{array}$ & $\begin{array}{r}(54) \\
(508) \\
(1,464)\end{array}$ & $\begin{array}{l}2 \text { Miscarriages } \\
1 \text { Miscarriage } \\
\text { None }\end{array}$ & $\begin{array}{r}320 \cdot 0 \\
124 \cdot 2 \\
65 \cdot 0\end{array}$ & $\begin{array}{r}(50) \\
(467) \\
(1,693)\end{array}$ \\
\hline Fourth & $\begin{array}{l}3 \text { Unsuccessful } \\
2 \text { Unsuccessful } \\
1 \text { Unsuccessful } \\
3 \text { Successful }\end{array}$ & $\begin{array}{r}263 \cdot 2 \\
177 \cdot 1 \\
152 \cdot 7 \\
87 \cdot 6\end{array}$ & $\begin{array}{r}(19) \\
(96) \\
(334) \\
(605)\end{array}$ & $\begin{array}{r}0 \cdot 0 \\
70 \cdot 6 \\
56 \cdot 7 \\
31 \cdot 6\end{array}$ & $\begin{array}{l}(14) \\
(85) \\
(300) \\
(570)\end{array}$ & $\begin{array}{l}3 \text { Miscarriages } \\
2 \text { Miscarriages } \\
1 \text { Miscarriage } \\
\text { None }\end{array}$ & $\begin{array}{r}307 \cdot 7 \\
121 \cdot 6 \\
110 \cdot 7 \\
59 \cdot 7\end{array}$ & $\begin{array}{r}(13) \\
(74) \\
(280) \\
(687)\end{array}$ \\
\hline
\end{tabular}

* Per 1,000 total pregnancies (numbers of total pregnancies shown in parentheses)

+ Per 1,000 'viable' pregnancies (numbers of 'viable' pregnancies shown in parentheses

TABLE II

(a) PERCENTAGES OF WOMEN WHO HAD NO FURTHER PREGNANCIES ACCORDING TO NUMBER OF PREGNANCIES EXPERIENCED AND THEIR SUCCESS

(b) PERCENTAGES OF SUCCESSFUL PREGNANCIES AT EACH STAGE FOR WOMEN WHO 'RETIRED' AND FOR THOSE WHO HAD AT LEAST ONE MORE PREGNANCY (Number of women and number of pregnancies in parentheses)

\begin{tabular}{|c|c|c|c|c|c|c|c|c|c|c|c|c|}
\hline & & & & & & No. & E Pregnan & far expe & enced & & & \\
\hline No. of & essfu & gnancies & & & 1 & & 2 & & & & 4 & 응 \\
\hline $\begin{array}{ll}0 & \cdots \\
1 & \cdots \\
2 & \cdots \\
3 & \cdots \\
4 & \cdots\end{array}$ & $\begin{array}{l}\cdots \\
\cdots \\
\cdots \\
\cdots\end{array}$ & $\begin{array}{l}\cdots \\
\cdots \\
\cdots \\
\cdots\end{array}$ & $\begin{array}{l}\ldots \\
\cdots \\
\cdots \\
\cdots\end{array}$ & $\begin{array}{c}4 \cdot 2 \\
24 \cdot 0 \\
= \\
-\end{array}$ & $\begin{array}{r}(497) \\
(4,451)\end{array}$ & 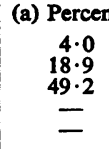 & $\begin{array}{r}\text { age havin } \\
(75) \\
(709) \\
(3,075)\end{array}$ & $\begin{array}{l}\text { bsequen } \\
13 \cdot 6 \\
26 \cdot 2 \\
46 \cdot 4 \\
57 \cdot 8 \\
-\end{array}$ & $\begin{array}{c}\text { pregnancies } \\
(22) \\
(130) \\
(623) \\
(3,075)\end{array}$ & $\begin{array}{l}40 \cdot 0 \\
32 \cdot 3 \\
44 \cdot 6 \\
54 \cdot 2 \\
65 \cdot 9\end{array}$ & $\begin{array}{r}(5) \\
(31) \\
(130) \\
(336) \\
(552)\end{array}$ & 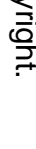 \\
\hline $\begin{array}{l}\text { Having no } \\
\text { Had at least }\end{array}$ & $\begin{array}{l}\text { pre } \\
\text { more }\end{array}$ & $\begin{array}{l}\text { cies } \\
\text { znancy }\end{array}$ & $\because$ & $\begin{array}{l}98 \cdot 1 \\
87 \cdot 7\end{array}$ & $\begin{array}{l}(1,089) \\
(3,859)\end{array}$ & $\begin{array}{l}\text { (b) } P \\
95 \cdot 8 \\
83 \cdot 7\end{array}$ & $\begin{array}{c}\text { centage } \\
(3,298) \\
(4,420)\end{array}$ & $\begin{array}{l}\text { ssful pr } \\
89 \cdot 5 \\
81.6\end{array}$ & $\begin{array}{l}\text { nancies } \\
(3,468) \\
(3,162)\end{array}$ & $\begin{array}{l}86 \cdot 4 \\
78 \cdot 6\end{array}$ & $\begin{array}{l}(2,464) \\
(1,752)\end{array}$ & \\
\hline
\end{tabular}

of women followed for 10 or 11 years after the first pregnancy was closely similar to that of women followed for 14 or 15 years; there was only a small excess of women with five or more pregnancies in the latter group. Therefore the data in Table II are not likely to be seriously affected by insufficient length of follow-up.

The rate of retirement from childbearing is influenced by age at first pregnancy and by the time interval between pregnancies, the latter being to some extent the result of different ideas of family planning (or lack of them) at different socioeconomic levels. Examination of these two aspects showed that although age at first pregnancy is a powerful factor the pattern of 'retirement' shown in Table II exists within age groups though the proportions of women retiring at any given time are higher among the older women. Perhaps less expectedly, it appeared that differences in the rate of retirement between social categories were almost wholly explained by differences in the age at first $\stackrel{\infty}{\stackrel{\odot}{2}}$ pregnancy. Thus the self-selection process seems to operate (possibly at slightly different levels) in all 3 . sections of the population.

If we divide women into groups according to the number of pregnancies they have had during the 0 follow-up period and examine the reproductive performance of these groups, as shown in the $\frac{7}{0}$ Figure, a striking pattern emerges. The greater the number of pregnancies that occurred during the $N$ follow-up period, the higher the incidence of $N$ unsuccessful pregnancies and the rate of perinatal $N$ mortality in all previous pregnancies. Rates for ${ }^{\omega}$ fifth and later pregnancies are not shown, because a high incidence of therapeutic abortion prevented $\stackrel{\circ}{=}$ the 'natural' outcome in many cases. It is, however, $\stackrel{\oplus}{\oplus}$ clear that the lowest rate of unsuccessful pregnancies ? in each cohort tended to coincide with the last 


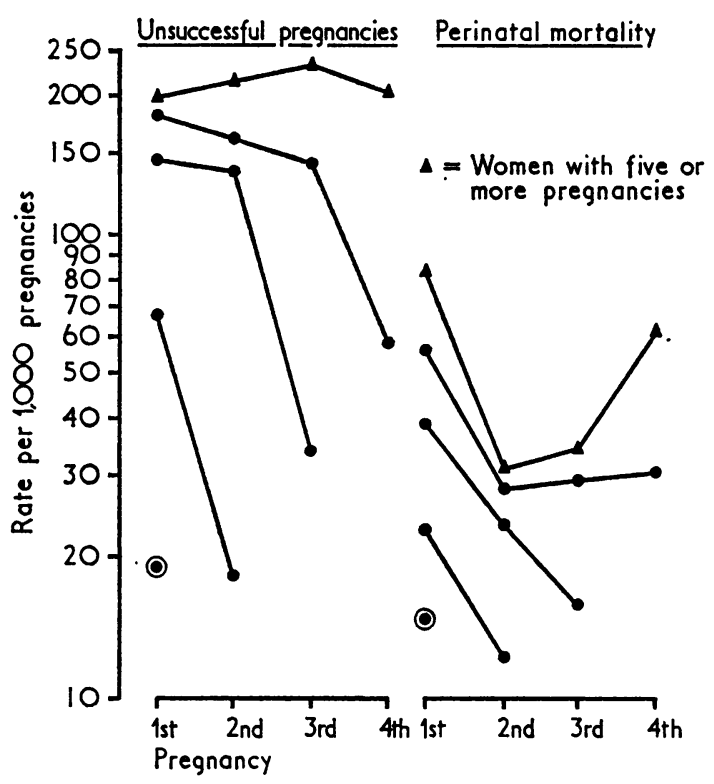

FIGURE Unsuccessful pregnancy and perinatal mortality rates for cohorts of women who had a given number of pregnancies during the follow-up period (1,089 women with one pregnancy, 1,649 with the follow-up period ( 1,089 women with one pregnancy, 1,649 with
two, 1,156 with three, 616 with four, and 438 women with five or more pregnancies).

recorded pregnancy, that is, the decision to retire appears to have been strongly influenced by success.

The majority of unsuccessful pregnancies were due to miscarriage, and it seemed possible that the distributions of causes of perinatal mortality might be influenced by the nature of the past obstetric history. There is, however, no evidence that this was so. Classification of perinatal deaths into clinico-pathological cause-groups (Baird and Thomson, 1969) gave no indication that the high rates of perinatal mortality among women with a poor past obstetric history could be attributed to any one cause or group of causes.

\section{Discussion}

The data show that at any pregnancy number the chances of having a miscarriage or a perinatal death are raised when previous pregnancies have been unsuccessful. Furthermore, women with good reproductive histories tend to stop having pregnancies sooner than those with poor histories. The latter process of 'selection by success' was relatively inefficient during the years covered by the survey (Thompson and Illsley, 1969). With more effective contraceptive methods, 'selection by success' is probably becoming more efficient (Peel, 1972).
The advent of a more efficient control of fertility implies a period of flux during which the population's reproductive habits undergo a change until a new stable pattern is achieved. It is, therefore, worth considering the extent to which such changes are likely to affect the national and hospital vital statistics.

At the level of national statistics, the birth rate should fall, and indeed it has done so. Since, however, most married women desire at least one child, fertility rates per 1,000 women should fall more drastically in older age groups. In Scotland, the fertility rates decreased between 1960 and 1970 by about $17 \%$ in married women aged $20-29$ years, by $30 \%$ in those aged $30-39$ years, and by $40 \%$ for women of 40-44 years. It is interesting to observe that the downward trends did not begin until 1964-65, years in which the 'pill' became more generally available, also that as yet there are no indications that a new stable pattern of age-specific fertility rates is being approached. This change in the age-specific fertility rates should lead to a substantial decrease in the incidence of infants with Down's syndrome since about $40 \%$ of such infants are born to mothers aged 40 years or more. It should also result in a gradual change in the distribution of births by parity. That this process is well under way is evidenced by parity distributions in Scotland: in 1960 first births accounted for $34 \%$ and fourth or higher for $19.6 \%$ of all births, while in 1970 the corresponding figures were $37 \cdot 1 \%$ and $15 \cdot 4 \%$ respectively. The increased proportion of first births is likely to result in a higher incidence of births under $2.5 \mathrm{~kg}$ and may partly explain the trend observed by Fryer and Ashford (1972).

Redistribution of births towards lower parities will in due course be reflected in a decrease of the average completed family size but more immediately in lower perinatal mortality rates. Since perinatal mortality rates are lowest at parities one and two (mostly second and third pregnancies) and then increase with parity, the diminished contribution of higher parities to the total of births will tend to lower the total perinatal mortality rate even in the absence of any real improvement in the health of the population or in the efficiency of medical services. For example, the perinatal mortality rate for Scotland fell from $25 \cdot 1$ to $24 \cdot 2$ per 1,000 births between 1968 and 1970 and nearly half of this reduction can be attributed to a shift in the parity distribution of births.

Maternity hospital statistics, where results are frequently presented in terms of pregnancy numbers rather than parities, will tend to show an increase of perinatal mortality and generally of unfavourable 
pregnancy outcomes at higher pregnancy numbers. This should not be interpreted as a failure of medical services without careful scrutiny. Suppose, for example, that the perinatal mortality rates shown in Table I remain static and that the rates of 'retirement' indicated in Table II increase so as to result in a distribution of pregnancy numbers similar to that of Scotland in 1970: the perinatal mortality rates in second, third and fourth pregnancies would then change from $19 \cdot 7,22 \cdot 7$, and $42 \cdot 3$ respectively to $19 \cdot 8,24 \cdot 1$, and $50 \cdot 4$ per 1,000 births.

To sum up, a slow but steady fall of the national perinatal mortality rate is not necessarily a cause for complacency, just as an apparent deterioration of results in higher pregnancies does not necessarily provide grounds for alarm; both movements may merely reflect changes in the reproductive habits of the population. One could even hazard a prediction that the rates for 1971 will show a further fall of perinatal mortality which may reflect nothing more than the increased number of therapeutic abortions, about $40 \%$ of which are performed on women with three or more children.

\section{SUMMARY}

From the reproductive histories of 4,948 married women followed for 10 to 15 years after their first pregnancies (during the years 1949-54) it was found that the chances of miscarriage or perinatal death $:$ are considerably raised when previous pregnancies 3 have been unsuccessful. Furthermore, women with $\stackrel{D}{?}$ good reproductive histories tended to stop having pregnancies sooner than those with poor histories. Improved methods of fertility control are probably $\bar{c}$ intensifying the process of self-selection for preg- 흘 nancy and may lead to changes in national and $\frac{\bar{\sigma}}{\vec{\sigma}}$ hospital statistics that are not necessarily the result $\stackrel{\mathbb{Q}}{\AA}$ of changes in public health or efficiency of medical care.

\section{REFERENCES}

BaIRD, D., and Thomson, A. M. (1969). The survey perinatal deaths re-classified by special clinicopathological assessment. In Perinatal Problems, edited by N. R. Butler, and E. D. Alberman, p. 200. Livingstone, Edinburgh and London.

Billewicz, W. Z., and Thomson, A. M. (1970). Body 6 weight in parous women. Brit.J. prev. soc. Med., 24, 을 97.

Fryer, J. G., and Ashrord, J. R. (1972). Trends in perinatal and neonatal mortality in England and Wales 1960-69. Brit. J. prev. soc. Med., 26, 1.

Peel, J. (1972). The Hull Family Survey. II. Family planning in the first five years of marriage. J. biosog $\overrightarrow{0}$ Sci., 4, 333.

Thompson, B., and ILLSLEY, R. (1969). Family growth Aberdeen. J. biosoc. Sci., 1, 23. 